\title{
ORGANIZATION DESIGN IN MOTION: DESIGNING AN ORGANIZATION FOR AGILITY
}

\author{
Shafiee Kristensen, Saeedeh (1); \\ Shafiee, Mitra (2); \\ Shafiee, Sara (3) \\ 1: Department of Management, School of Business and Social Sciences, Aarhus University (AU); \\ Milestones Systems A/S; \\ 2: Science and Research Branch, Faculty of Management and Economics, Islamic Azad University, \\ Tehran; \\ 3: Department of Mechanical Engineer
}

\begin{abstract}
Increasingly competitive and multifaceted business landscapes and the accelerating pace of innovation require organizations to build in-house capability to evaluate the effectiveness of their design and redesign their organizational structure to drive agile product development. The purpose of this research is to examine how the ability of an organization to implement agile is affected by the organization design. A case study based on 35 semi-structured interviews and field observations at a leading, large-size, Danish software development company was carried out. Adopting the contingency perspective, this paper presents the relevant organizational elements that can increase organizational agility and how the companies can leverage the advantages of the design. Accordingly, it provides a framework that compromises eighteen core organizational practices grouped into four categories (organizational structure and governance, culture and people, IT tools and data infrastructure, and processes) to understand the effect of organization design on agile product development.
\end{abstract}

Keywords: Organizational processes, Communication, Organisation of product development

\section{Contact:}

Shafiee, Sara

Technical University of Denmark (DTU)

Department of Mechanical Engineering

Denmark

shafieesara7@gmail.com

Cite this article: Shafiee Kristensen, S., Shafiee, M., Shafiee, S. (2021) 'Organization Design in Motion: Designing an Organization for Agility', in Proceedings of the International Conference on Engineering Design (ICED21), Gothenburg, Sweden, 16-20 August 2021. DOI:10.1017/pds.2021.496 


\section{INTRODUCTION}

Increasingly competitive and multifaceted business landscapes, commonly referred to as VUCA (volatile, uncertain, complex and ambiguous) environments (Bennett and Lemoine, 2014), require organizations to be adaptive - implementing strategies and allocating resources rapidly and effectively in response to opportunities and challenges in global and local markets (Fjeldstad et al., 2012). A VUCA world highlights the significance of designing ambidextrous organizations, i.e. an organization to be able to balance two diametrically opposed organizational qualities - adaptability and alignment. Adaptability is the ability to respond to change and alignment is the ability to leverage existing ideas and exploit markets. The organization that successfully reconciles both is called agile and is rewarded with a significant competitive advantage, (Nijssen and Paauwe, 2012). According to these researchers, an agile organization is able to balance both control and autonomy through its' organizational infrastructure. Achieving agility is a key driver for organizations keen on reducing time to market, fostering innovation and tackling complexity (De Smet et al. 2018). Recent research has suggested that organization design can be used as a key enabler to unlock organizational agility (e.g., Puranam, 2018; Puranam et al., 2014; Benner and Tushman, 2003; Bower and Christensen, 1995; Jacobides, 2007).

This article discusses the role of the organization design in enforcing organizational agility. It provides a preliminary framework that compromises eighteen core agile principles of organization design grouped into four categories (organizational structure, culture and people, technology, and processes) to understand the effect of organization design on agility. The developed framework is based on organic organizational structure (Contingency Theory). As a useful roadmap for organizations to improve organizational agility through organic structure and organizational learning, the proposed framework also contributes to practice through the framework's analytical potential and improved understanding of the relationships between organization design and organizational agility. Clearly, the framework presented in this paper is merely a starting point for developing models that are more sophisticated in the future.

\section{THE CURRENT STATE OF RESEARCH}

Organizational agility is mainly defined as an organization's ability to be adaptable in response to environmental changes. As a dynamic capability for organizations operating in a highly dynamic environment, organizational agility is the capacity to sense and respond rapidly to changing customer needs, to make decisions rapidly, and to reallocate resource quickly as circumstances change (Nijssen and Paauwe, 2012; Wawarta and Heracleous, 2018). However, too much exploration and flexibility at the expense of exploitation and efficiency (failure trap) is as dangerous as too much exploitation at the expense of exploration (success trap). The inability of Nokia and Motorola to simultaneously improve competence in existing domain (efficiency) and leaving latitude for real-time adjustment of actions in response to actual events (flexibility) resulted in the decline of the organizations. Therefore, agility is recently defined as achieving this balance (Rey et al., 2019) and some researchers (e.g. Gibson \& Birkinshaw, 2004) believe that a successful agile organization is able to simultaneously develop new products and maintain efficiency by aligning themselves around adaptability. What leaders need is to evaluate their organization design as the key driver of organizational agility.

We witness a paradigm shift in the ways that organizations achieve to balance efficiency and flexibility. It is a clear and categorical shift from the area in the direction of the machine metaphor to metaphor of a living organism (Mintzberg, 1992). The shift is happening in the face of organizational challenges brought by the "digital revolution" that is transforming industries, economies, and societies. As a result, responding like a living organism, i.e. having organizational agility, is one of the top priorities for companies (De Smet, 2018).

Agile organizations as a living organism mobilize quickly, are nimble, empowered to act, and make it easy to act. They have evolved to thrive in an unpredictable, rapidly changing environment. These organizations are both stable and dynamic. Based on the literature (e.g. Ebrahim et al., 2018; Laloux and Wilber, 2014; Kristensen, 2019; Moreira, 2017), the new agile organization is designed to:

- co-create value with and for all of the stakeholders through recognizing the abundance of opportunities and resources available.

- enable employees to be highly engaged, take care of each other, figure out ingenious solutions, and deliver exceptional results through clear accountabilities. 
- embrace uncertainty and be the quickest and most productive in trying new things in order to minimize risk; evolve continually; and embrace uncertainty and ambiguity.

- empower employees to take full ownership, confident to drive the organization toward fulfilling its purpose and vision.

- focus on customers to fluidly adapt to environmental changes, and are open, inclusive, and nonhierarchical.

The idea of organic organization originated from a body of thought called the contingency approach in organizational research. Contingency theories are classes of behavioural theory that state that there is no universal way of managing or organizing a company, and that the organizing style is dependent on the situational constraints of environment in which the company operates. This view is based on the approach that treats organizations as open systems that have to interact with their environment in order to be successful. This, in turn, implies that organizations cannot be considered and analysed in isolation of the environment. Contingency theory does not prescribe any best way to organize but rather suggests that organization design choices need to be contingent on both the strategy selected and the environment in which the business is operating. The main premise of the contingency theory is that organizational effectiveness can be achieved by fitting the characteristics of the organization to contingencies that reflect the situation of the organization (Donaldson, 2001, Lawrence and Lorsch, 1967). Thus, in order to maintain effectiveness, the organizations have to adapt over time to fit changing contingencies. Contingency theory has been extended with complementary systems theory, which comes to organization design from the field of economics (Milgrom and Roberts, 1995). The notion of complementarity holds that design choices work as coherent systems and that the application of one practice will influence the results of a corresponding practice - whether positive or negative.

\section{RESEARCH DESIGN}

This paper is extracted from part of research work done for a master's dissertation project. In this research project, Kristensen, (2019) used a mixed approach research design (qualitative and quantitative) to investigate the organizational agility in a single case study. The researcher collected the data through surveys, qualitative interviews and observations to provide a rich description of organizational agility, the role of organizational agility in innovation performance and the role of different organization design elements to achieve it. This research project focuses on a single in-depth case study (Yin, 2013) of a Danish software development company's adoption of an agile approach to product development. At the time of this study, the case company possessed a leading position in Video Management Software market and could be representative of large companies that produce complex high-technologyempowered solutions. The unit of analysis in this case study is the product development projects.

In this paper, we use the data collected through semi-structured interviews with 35 employees (2 executives, 5 directors, 6 department managers, 5 product designers, 7 product owners, and 10 software developers) as well as two direct observations to understand how agile teams work together. First, the transcripts were analysed to identify the different types of organizational elements that improve organizational agility. In this phase, the elements of the agile organization units were mapped to the following categories: organizational structure and governance, culture and people, IT tools and data infrastructure, and processes. Then, the interview transcripts were coded on the basis of identified themes. These data were analysed individually by each researcher, and then authors gathered to discuss main insights.

\section{FINDINGS: ORGANIZATIONAL ELEMENTS TO ACHIEVE AGILITY}

Given organizing as a problem-solving process through which solutions should be discovered for balancing efficiency and flexibility as a universal problem of organization (Puranam, 2018), organizational agility cannot be explored and implemented apart from organizational elements such as structure, role allocation, culture, technology, processes, motivation and coordination. Taking this approach to organizational design can both fill this gap in research and provide an understanding of the bundles of co-occurring organizational elements or practices that enable new theorizing (Puranam et al., 2014). This research uses in-depth case study, 35 semi-structured interviews, and individual observations to summarize the design characteristics of an agile organization. Accordingly, Figure 1 
summarizes the four categories and their core agile principles to understand the effect of organization design on agility.

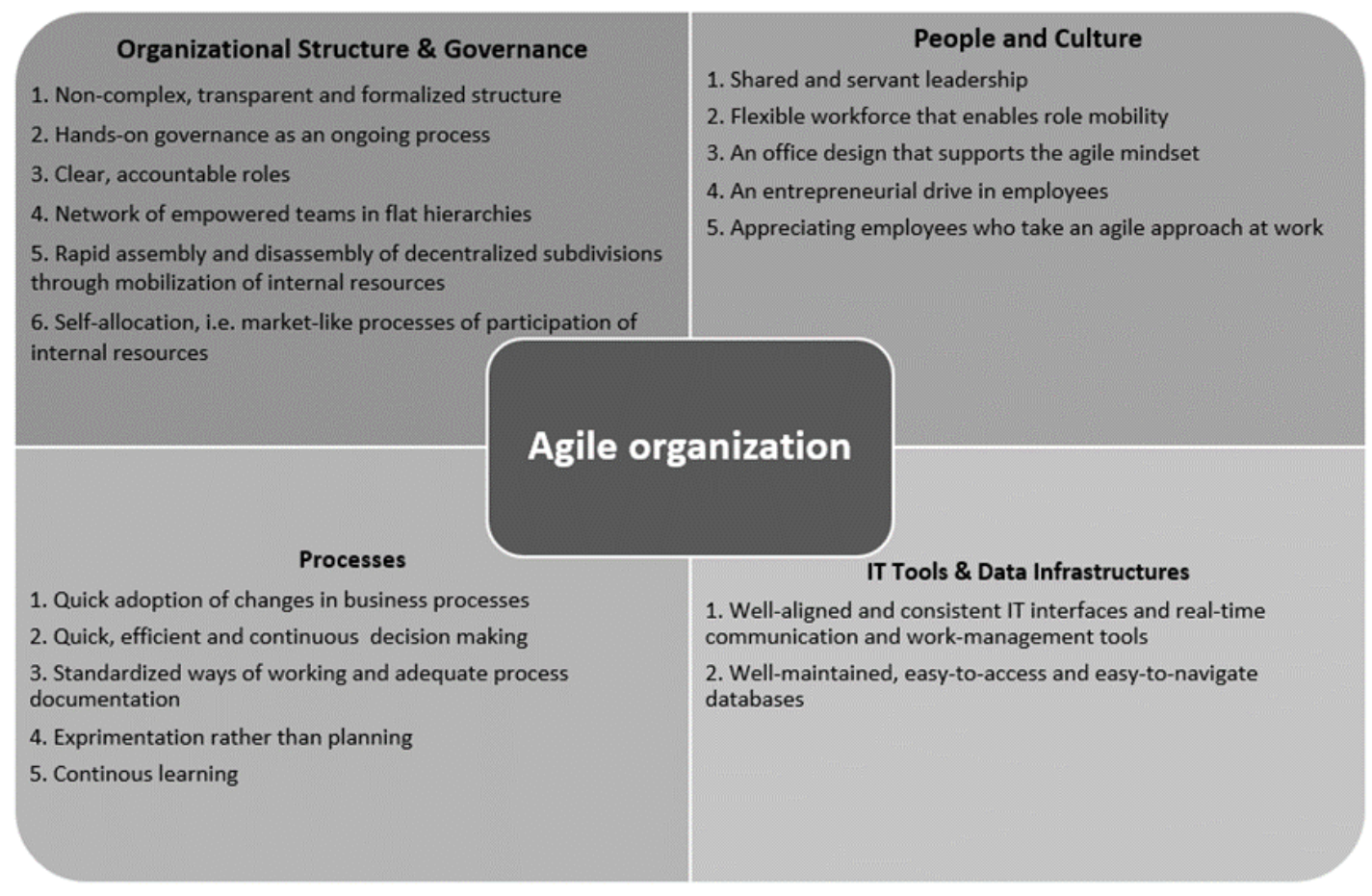

Figure 1. Design characteristics of an agile organization

\subsection{Organizational Structure and Governance}

Organizational structure shapes the resources and organizational capabilities and develops them. It also determines lines of accountability and gives direction to the internal interactions in the organization. Boundaries, guidelines and rules required for steering and decision making, i.e. governance, are closely connected to the structure. Given both are considered as key factors in achieving organizational agility, an agile firm should have some main characteristics in terms of structure and governance:

1. Agile organizations possess non-complex, transparent and formalized structure. Rather than a complex matrixed organization, an agile organization has an easy to understand setup with a similar logic across departments and regional offices. This enables leaders, teams and entire organization to anticipate change in the organization in response to the environment. The elegant simplicity of the structure is what makes it both incredibly powerful and somewhat hard to grasp as an operating model. It also create a clear roadmap in which functions evolve to become robust communities of knowledge and practice, enabling organizations to build depth and specialization-attract and develop experts who "speak the same language" - and providing stability and continuity over time as people rotate between different operating teams (Kristensen, 2019; The Corporate Rebels, 2019).

2. Another lever for increased agility is good hands-on governance as an ongoing process that happens on a team-by-team level. The effective governance creates an interaction point where relevant teams get the decision rights and make the decisions fast in highly-productive coordinating forums (Alberts and Hayes, 2005). The self-organized governance methods and meetings used in agile organizations empower people in day-to-day activities and enables any employee to contribute to the evolving structure of the organization. Some steering committees are chartered and operate effectively to cut across the normal hierarchy and get the right people talking to one another about customers, objectives, conflicts, resources, and performance on a regular basis. Non-agile firms are relatively low in dynamism and most often characterized by reliability, standard ways of working, risk aversion, silos, and efficiency. Employees are not aware of the space where they can all find their own empowerment, and there is a lack of governance system or framework that protects that space regardless of the actions of any one individual, whatever his or her position (Kristensen and Shafiee, 2019).

3. Clear, accountable roles are another organizational element that can improve agility. In an organization where employees can transparently view what every employee's purposes and 
accountabilities are they can interact effectively without losing time or waiting for manager approvals. Through governance meetings and technology tools, any lack of clarity can be addresses about roles proactively and immediately. This enables employees to share roles and have multiple roles (Kristensen, 2019).

4. An important part of designing for agility is a shift away from hierarchical organizational structures toward models where work is accomplished in teams within flat hierarchies. Traditional organizational model — with hierarchical job levels based on expertise in a specific area-cannot make organization highly agile. Instead, leading companies are pushing toward a more flexible, team-centric model (Nijssen and Paauwe, 2012, McDowell et al., 2016). Whatever a hierarchical organization chart says, real, day-to-day work gets done in networks. Therefore, the organization of the future is a "network of teams". Top companies are built around systems that encourage teams and individuals to meet each other, share information transparently, and move from team to team depending on the issue to be addressed. A deep analysis of organizational structure using the number of layers, span of control, employees experience and insights and leadership challenges can identify how flat a firm is. In a flat organizational structure, communication is more efficient, and the valuable insights are not lost (The Corporate Rebels, 2018).

5. A lever for improving the balance between efficiency and flexibility in a truly agile organization is decentralization, i.e. delegation of the tasks to self-managing teams which then enables lateral coordination across hierarchies or functions and thereby sharing, and ultimately creation of new knowledge (Hansen et al., 2018, Alavi et al., 2014). Agile organizations such as Spotify take an organizing approach with temporary decentralization, which starts out with a decentralized structure and later reintegrates. In other words, agile teams are assembled, and dissolved to seize a market opportunity or to innovate while keeping the overall structure of the company intact.

6. Given the autonomy of temporarily decentralized teams, this design itself can create an environment in which people self-select to join a project (Burton et al., 2017). Some studies (e.g. Brady and Davies, 2004, Wigger and Agnete Alsos, 2018) show that a more market-like processes of participation of internal resources in the projects and then working in self-organizing subdivisions, guided by a strong project goal and specific time limits can foster the utilization of new knowledge combinations.

\subsection{People and culture}

Culture as the set of values, beliefs, assumptions and ways of interaction that contribute to the unique organizational, psychological and social environment of an organization nurtures the in-house capacity for organizational agility. Agile transformation required a culture shift from command-and-control to an autonomy-oriented culture that puts people at the centre and engages and empowers everyone in the organization, and fosters fast responses (Wawarta and Heracleous, 2018). The following cultural characteristics are closely connected to agility:

1. Shared and servant leadership is a critical aspect of organizational culture most related to agility. Organizations that experience this transformation have invested in leadership which empowers, coaches and motivates its people and enable them to learn and develop the most relevant capabilities. Leaders can be better (and need to be trained) at embracing shared and servant leadership by more frequently incentivizing team-oriented behaviour and investing in employee development (Thomas and Velthouse 1990).

2. Another element of organizational structure is a cultural context that supports role mobility. When people move regularly between roles and teams vertically and horizontally, based on their development plans, they can learn and develop their skills, knowledge and networks. This requires firms to maintain an open talent marketplace where available roles, tasks, and/or projects are clearly communicated and a system in which key resources can be deployed and redeployed between initiatives as priorities (Ebrahim et al. 2018; Kristensen and Shafiee, 2019).

3. While the agile approach to work may not be the right fit for all employees, the appreciation of those employees who proactively take responsibilities, bring forward new ideas and adopt new roles in pursuit of learning can be a powerful way to create an agile culture in which everyone have the feeling of belonging as being heard, considered and respected (Wawarta and Heracleous, 2018). This behaviour that displays a internalized motivation and commitment is empowered by the servant leadership style (Thomas and Velthouse, 1990). Development of such a mind-set enables the firm to make decisions in a more decentralized and consequently more agile way. 
4. Office design can support and shape an agile culture. The office is the embodiment of an agile mind-set. Therefore, role mobility, transparency and nimbleness can require a working environment that is flexible and intuitive (Rob, 2015), an office built essentially with versatile moving parts that are primed to deliver on core promises:

- Competently supports the dynamic, self-managing design of networked teams,

- Adapts, reconfiguring to empower activity-based working, and

- Efficiently uses space.

5. The cultural environment needs to foster by an entrepreneurial drive, i.e. people who are enthusiastic and intrinsically motivated to learn and innovate. They proactively identify and pursue opportunities to develop new initiatives, knowledge, and skills in their daily work. Autonomy, servant leadership and role mobility as cultural norms reinforced through positive peer behaviour and influence in a high-trust environment can nurture this entrepreneurial spirit (Ebrahim et al., 2018).

\subsection{IT tools and data infrastructure}

To accelerate innovation, reduce time-to-market and meet changing customer in order to maintain the competitive advantage, agile organizations need to offer solutions, products and services enables by emerging technology. This requires these firms to continually and rapidly evolve their operating processes, which will require evolving technology architecture, interfaces, and tools. Technology wise, the following two elements are of special importance:

1. Well-aligned and consistent IT interfaces and real-time communication and work-management tools are integral component of any agile organization. Leveraging these tools and interfaces not only makes the integration of different sources of data plausible but also minimizes handovers and interdependencies that can slow down production cycles. The agile organization integrated a range of emerging technologies with delivery practices into organization and business to build, implement and maintain these tools and interfaces. For example, for many large organizations, the shift from command and control to a self-organized adaptable system is a significant change that requires digital tools to link the autonomous networks of teams. Automating interactions and connections in an organization's network of teams can make processes effective and efficient and allow the organization to scale without hierarchical command and control (Page et al. 2016). Large, established organizations can increase autonomy and self-management with increased visibility that technology such as Scrum, GlassFrog, Slack, SAFe and DevOps provide. According to Wawarta and Heracleous (2018), IT interface alignment and data standardization requires three steps:

- $\quad$ Evaluating the systems, components, interfaces and supported business processes

- Defining a target landscape describing interfaces clearly

- And finally, developing a digital transformation strategy for implementing the desired plan

2. Easy to access and navigate databases to support aligned interfaces and tools help realize the dynamic capabilities in an agile organization. For example, the agility in knowledge reintegration and refinement in an innovation process can be facilitated by an integrated database infrastructure which contains the created knowledge well-documented as well as by the user-friendly interfaces and an inclusive access management which the databases are characterized by. This can effectively tune the level of interdependencies and the amount of required coordination and leverage the transparency (Tallon and Pinsonneault, 2011).

\subsection{Processes}

1. To sense and seize the opportunities, employees should be able make a quick adoption of changes in business processes. As already discussed, this is rooted in contingency theory. Accordingly, there is no standard best way of designing the organization; rather, the design must be always contingent upon the external and internal challenges, opportunities and changes. While for an agile firm, this means effective adjustment to environmental changes with respect to business processes (Winter, 2003), this does not underestimate the significance of standardized ways of working that foster efficiency and provide the basis for the quick adoption of changes (Trkman, 2009).

2. Agile firms emphasize quick, efficient and continuous decision making. Due to the organizational structure and IT interfaces that leverage transparency in information flow and accountabilities and roles, they have insight into what types of decisions are made and who makes them. They rely on small decisions in rapid cycles and then testing the decision in practice and then adjusting them as 
needed to the nest iteration. People closest to where the work happens have the authority to make decisions that affect the implementation of their day-to-day activities. This is supported by the governance systems and distributed authority element rather than delegated authority and centralized decision making that happened top-to-bottom (Robinson, 2015). By not escalating all decisions to higher levels of authority, the lead times can be shortened. This due to the lack of local context among higher managers when making decisions that concerns the daily work of knowledge workers (Scaled agile framework, 2015).

3. In an agile organization, it is this stable backbone that becomes a springboard for the company, an anchor point that doesn't change while a whole bunch of other things is changing constantly. In other words, the standardized way of working and adequate process documentation makes the nimbleness, speed and responsiveness possible. Moreover, this enables the continuous improvement of organizational and business processes (Trkman, 2009). A balance should be maintained between process change and continuity, between innovation and efficiency. Although standardization and documentation of processes in an adequate way can increase efficiency, too much standardization can also foster inertia.

4. In traditional firms, 'planning and predicting' is the common practice, which will not the best approach in the VUCA world. Agile organization embrace experimentation not only in their products and service offerings but also in their organizational efforts. Experimentation, rapid iteration and acknowledging that mistakes can be made needs a learning and safe environment in which people dare to fail (Ebrahim et al., 2018). For example, in a Design Thinking approach to innovation, team members are accountable from the end-to-end outcome of their work. Relying on an iterative, nonlinear process which favours ongoing experimentation, team members are empowered to evaluate the desirability, feasibility and viability of the product. This approach saves time, reduces rework, creates opportunities for innovative solutions, and increases the sense of ownership, accountability, and accomplishment within the team (Shafiee et al. 2020).

5. In an agile organization where empowerment, role mobility and experimentation are emphasized, exceptional opportunities for learning are always available and never ignored by the employees. People pick up new roles, put forward their new ideas, experiment them and dare to make mistakes. In organizations like Buutzorg, Spotify, Morning Star and some other companies with the same approach of working, people are constantly learning by making decisions and seeking advice, working in voluntary task forces, picking up skills and knowledge that elsewhere would be concentrated in management and staff functions (Laloux and Wilber, 2014).

\section{CONCLUSION}

Built on contingency perspective, this framework for an agile organization design highlights that performance outcomes of an organizational unit are a result of the fit between the unit's external context and internal arrangements. The agile organization's performance outcomes hinge on the coherence among these components and misalignments within these organization design components can lead to a decline in the firm's performance. Each one of these componentsof the design should work to support agile product development. The more that structure, processes, IT infrastructure, culture and people practices reinforce the agile practices and behaviours, the better able the organization should be to achieve its goals. However, they are tightly nested and interwoven and need to be well aligned. For example, if we design the organization to delegate tasks to self-managing temporary teams but we still have a culture of centralized authority with traditional leadership principles, we have a situation where the organization requires a decentralized environment led by servant leaders, while it does not possess such a cultural component to nurture that structural element. Organizing for agility is the deliberate process of reconfiguring structure, processes, IT infrastructure, culture and people practices towards value-creating and value-protecting opportunities. The design is not an end in itself; it is simply a vehicle for accomplishing the strategic priorities in an agile organization. As an invisible construct, organizational elements of design can be used to harness and direct the energy of the people and to create an effective organization capable of achieving the business strategy. The design criteria defined in this paper differentiate the agile organization and help it execute its strategy. Although strategy emerges organically from the collective intelligence of selfmanaging teams in an agile organization, the strategic objectives of agile firms concentrate on 
accelerating innovation, reducing time-to-market, operating with flexibility and pace, and facilitating agile use of resources.

The old rules of organization design were focused on pushing a defined set of products or services to a steady set of customers with predictable buying habits being served by a known set of competitors. In that predictable world of certainties, the pursuit of efficiency was the common DNA strand in all of organizational hierarchies with the most powerful governance bodies at the top with goals and decision rights flowing down the hierarchy. For many industries that world is gone. Hence, the new rules organization design is shifting from a pursuit of efficiency to a focus on flexibility as well. These agile organizations act as a network of teams operating in rapid learning and fast decision cycles and are being designed to focus on action with fluid teams built around end-to end accountabilities and leadership that shows direction and enables actions.

In summary, today's environment is pressing organizations to become more agile; in response, a new organizational form is emerging that exhibits the organizational elements discussed above. These elements and the agility practices defined for each can enable organizations to balance stability and dynamism and thrive in an era of unprecedented opportunity. Although some agile organizations from different industries have been successful in implementing their organizational transformation, there are cases of failure as well. We tend to know little about the practicality and workability of these practices. The next step in research is to conduct case studies to get more insight into the actual practices that contribute to organizational agility and the relevant challenges and consequences. It can enable us to explore and analyse different organizational practices and behaviours as well as their influence in different organizational settings. Moreover, the future research can also focus on understanding the reasons for the failure and success of implementation organizational transformation towards agility. The other future focus would be to investigate the interactions of these four elements and subsequently sub-elements.

\section{REFERENCES}

Alavi, S., Dzuraidah A. W., Norhamidi, M. and Arbab Shirani B. (2014), “Organic Structure and Organisational Learning as the Main Antecedents of Workforce Agility”, International Journal of Production Research, Vol. 52 No. 21, pp. 6273-6295. http://doi.org/10.1080/00207543.2014.919420

Bennett N. and Lemoine J.G. (2014), "What VUCA Really Means for You”, Harvard Business Review, http://doi.org/2014/01/what-vuca-really-means-for-you

Bower, J. L. and Christensen, C. M. (1995), "Disruptive Technologies: Catching the Wave", Harvard Business Review, Vol. 73 No. 1, pp. 43-53.

Brady, T. and Davies, A. (2004), "Building Project Capabilities: From Exploratory to Exploitative Learning", Organization Studies, Vol. 25 No. 9, pp. 1601-21.

Burton, R. M., Håkonsson, R. M., Nickerson, J., Puranam, P., Workiewicz, M. and Zenger,T (2017), “GitHub: exploring the space between boss-less and hierarchical forms of organizing”, Journal of Organization Design, Vol. 6 No1, pp. 10. https://doi.org/10.1186/s41469-017-0020-3

De Smet, A., Lackey, G., Lurie, M. and Murarka, M. (2018), The Five Trademarks of Agile Organizations, McKinsey\&Company.

Donaldson, L. (2001), The Contingency Theory of Organizations, Sage Publications.

Ebrahim, Sh., Krishnakanthan, K. and Thaker, Sh. (2018), Agile Compendium, McKinsey\&Company.

Fjeldstad Ø.D., Snow CC, Miles R.E. and Lettl C. (2012), “The Architecture of Collaboration”, Strategic Management Journal, Vol. 33 No. 6, pp. 734-750. https://doi.org/10.1002/smj.1968

Gibson, C. and Birkinshaw, J. (2004), “The Antecedents, Consequences, and Mediating Role of Organizational Ambidexterity", The Academy of Management Journal, Vol. 47 No. 2, pp. 209-226. Retrieved December 6, 2020, from: (http://www.jstor.org/stable/20159573)

Hansen, N.K., Wolfgang H. G. and Swart, J. (2017). "HRM in Dynamic Environments: Exploitative, Exploratory, and Ambidextrous HR Architectures", The International Journal of Human Resource Management, https://doi.org/10.1080/09585192.2016.127

Heracleous L. and Oliver D. (2018), "Organizational design for agility", In: Prange, Ch. and Heracleous L. (Eds), Agility X: How organizations thrive in unpredictable times, Cambridge: Cambridge University Press, pp. (114-136).

Jacobides, M. (2007), "The Inherent Limits of Organizational Structure and the Unfulfilled Role of Hierarchy: Lessons from a Near-war", Organization Science, Vol. 18 No. 3, pp. 455-477. https://doi.org/10.1287/orsc.1070.0278

Kristensen, S. Sh. (2019), Rethinking the Potential Organization of Technology Group at Milestone, Master Thesis, Technical University of Denmark. 
Kristensen, S. Sh. and Shafiee, S. (2019), "Rethinking organization design to enforce organizational agility", paper presented at The 11th Symposium on Competence-Based Strategic Management, University of Stuttgart, 26-27 September 2019.

Laloux, F. and Wilber, K. (2014), Reinventing Organizations: A Guide to Creating Organizations inspired by the Next Stage in Human Consciousness, Nelson Parker.

Lawrence, P.R. and Lorsch J. W. (1967), Organization and Environment, Boston, MA: Harvard Business School, Division of Research Cambridge, Harvard University Press.

McDowell, T., Agarwal, D., Miller, D., Okamoto, T. and Page, T. (2016), "Organizational Design: The Rise of Teams", Deloitte Global Human Capital Trends 2016.

Milgrom, P. and Roberts, J. (1995), “Complementarities and Fit: Strategy, Structure, and Organizational Change in Manufacturing", Journal of Accounting and Economics, Vol. 19 No. 2, pp. 179-208. https://doi.org/10.1016/0165-4101(94)00382-F

Mintzberg, H. (1992), Structure in Fives: Designing Effective Organizations, Englewood Cliffs, NJ: Prentice Hall.

Moreira, M. E. (2017), The agile enterprise: Building and running agile organizations, Apress, Berkeley, CA.

Nijssen M. and Pauwe, J. (2012), "HRM in Turbulent Times: How to Achieve Organizational Agility?", The International Journal of Human Resource Management, Vol. 23 No. 16, pp. 3315-3335, https://doi.org/10.1080/09585192.2012.689160

Page, T., Rahnema, A. Murphy, T. and McDowell, T. (2016), Unlocking the Flexible Organization: Organizational sesign for an Uncertain Future. Deloitte.

Rey C., Pitta N., Ramonas D., Sotok P. (2019), “Agile Purpose: Overcoming Bureaucracy”, In: Rey C., Bastons M. and Sotok P. (Eds), Purpose-driven Organizations, Palgrave Macmillan, Cham, pp. (75-86). https://doi.org/10.1007/978-3-030-17674-7_6

Robinson, B. (2015), Holacracy: The New Management System for a Rapidly Changing World. Henry Holt and Co.

ScaledAgile. (2015), Lean-Agile Mindset Abstract. Available at: (http://www.scaledagileframework.com/leanagile-mindset/)

Shafiee, S., Haug, A., Shafiee Kristensen, S. and Hvem, L. (2020), “Application of Design Thinking to Product Configuration Project”, Journal of Manufacturing Technology Management, Vol. 32 No.1, pp. 219-241.

Tallon, P.P. and Pinsonneault, A. (2011), "Competing Perspectives on the Link between Strategic Information Technology Alignment and Organizational Agility: Insights from a Mediation Model”, MIS Quarterly, Vol. 35, pp. 463-486. https://doi.org/10.2307/23044052

The Corporate Rebels, (2018), Busting the myth: organizations with no hierarchy don't exist. Available at: (https://corporate-rebels.com/busting-the-myth/)

The Corporate Rebels, (2019), 5 ways to create a radically transparent work culture. Available at: (https://corporate-rebels.com/transparent-work-culture/)

Thomas, K.W. and Velthouse B.A. (1990), "Cognitive Elements of Empowerment: An "Interpretive" Model of Intrinsic Task Motivation", Academy of Management Review, Vol. 15, pp. 666-681.

Trkman, P. (2009), “The Critical Success factors of business process management”, International Journal of Information Management, Vol. 30, pp. 125-134. https://doi.org/10.1016/j.ijinfomgt.2009.07.003

Wawarta C.H. and Heracleous L. (2018), "Playfulness and Agile Strategizing", In: Prange, Ch. and Heracleous L. (Eds), Agility X: How organizations thrive in unpredictable times, Cambridge: Cambridge University Press, pp. (99-113).

Wigger, K. and Agnete Alsos, G. (2018), "Resource Mobilization for Temporary Opportunities”, Academy of Management Proceedings, AOM Chicago.

Winter, S.G. (2003), “Understanding Dynamic Capabilities”, Strategic Management Journal, Vol. 24, pp. 991995. https://doi.org/10.1002/smj.318

Yin, R.K. (2013), Case Study Research: Design and Methods, 5th ed. Thousand Oaks: Sage Publication. 


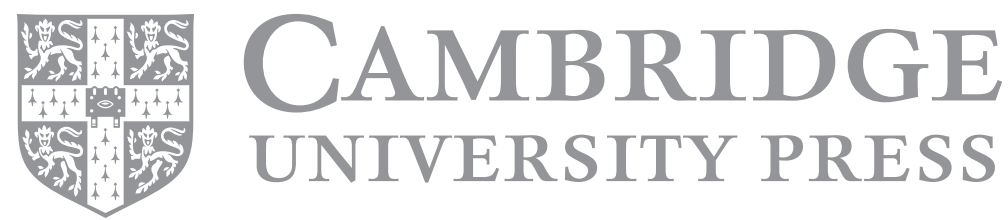

